\title{
Assessment of Antenatal Maternity Service Quality at Mafikeng Provincial Hospital, South Africa
}

\author{
Munyaradzi Mushunje \\ Sam Lubbe \\ Jan Meyer
}

\section{Abstract}

The purpose of this study was to assess antenatal maternity service quality among patients at Mafikeng Provincial Hospital (MPH) in the North - West Province. Quantitative research using a SERVQUAL based questionnaire was carried out to determine the expectations and perceptions of antenatal patients on MPH antenatal service quality. Correlation were used to determine the relationship of expectations and perceptions on service quality. A total of 70 questionnaires were successfully completed. The results of the study showed that antenatal patients have high expectations of MPH antenatal service quality and patients generally had positive perceptions on the quality of service they receive. Mixed responses were however obtained in areas involving clinic operating times and the ability of maternity staff to perform work right the first time. Findings of this research study were used to draw conclusions on antenatal care service quality.

Keywords: Antenatal, maternity, public service, quality of service, SERVQUAL

\section{Introduction}

Public sector organisations in South Africa have come under pressure to deliver quality service and improve on efficiency. In today's global 
environment, delivering quality service is an essential strategy for organisational success (Ramseook-Munhurrun et al. 2010). Hospital service quality has become a determinant of organisational success and survival in an environment where patients have become critical and selective of the quality of health services they receive (Mensah, Yamoah \& Adom 2014). This research determined the expectations and perceptions of antenatal patients of MPH Service Quality.

In reviewing the research, key concepts were derived from the problem statement and in turn used to search for literature. A literature review concept matrix was developed and different sources were classified according to the concepts. This paper is presented as follows: Introduction, the problem statement, research used and concludes with recommendations.

\section{Problem Statement and Research Questions}

Mortality rate among women of reproductive age has increased in South Africa (Burton \& Acquah 2014). The level of maternal mortality is a concern to the South African Government as expressed in its population policy (Millennium Development Goals Country Report 2013). Millennium goal number five seeks to improve maternal health and had set a target of Maternal Mortality Rate (MMR) for South Africa at 38 per 100000 live births by the year 2015 (Millennium Development Goals Country Report 2013).

The South African Government has taken steps towards reducing MMR, including implementing policies that emphasize primary health care and providing free antenatal care (Amnesty International Report 2013). The government has, however, failed to reach the target of millennium goal number five that was set to have achieved a reduction in the maternal mortality ratio of 38 deaths per 100000 live births by 2015 (Millenium Development Goals Report 2013).

Provision of quality antenatal maternity services remains a component towards reducing maternal mortality rates and ensuring happy mothers and healthy babies. This paper therefore investigates the quality of antenatal maternity services that pregnant women receive from Mafikeng Provincial Hospital in the Northwest Province.

This research answered the following questions:

a) What expectations do maternity patients have of Mafikeng Provincial Hospital's service quality? 
b) What perceptions do Maternity patients have of Mafikeng Provincial Hospital service quality?

c) How are expectations and perceptions of maternity patients' contributors of MPH service quality?

\section{Overview of Theory}

Antenatal care (ANC) is the care, supervision and attention given to a pregnant woman and foetus during pregnancy up to delivery. It is an entry point for a pregnant woman to receive a broad range of health promotion and preventive health services (Baffour-Awuah, Mwini-Nyaledzigbor \& Richter 2015). The role antenatal care plays in reducing maternal mortality is not debated. It is agreed that ANC maximizes positive pregnancy outcomes and reduces maternal and perinatal mortality (Afulani 2015; Baffour-Awuah, MwiniNyaledzigbor \& Richter 2015; Ejigu, Woldie \& Kifle 2013; Fagbamigbe \& Idemudia 2015. Lori et al. 2014; Naariyong et al. 2012; Villadsen et al. 2015).

In a bid to improve on the quality of antenatal care services provided to pregnant women and reduce maternal mortality rates in developing countries, The World Health Organisation introduced the Focussed Antenatal Care (FANC) programme. FANC is aimed at reducing waiting times during antenatal visits while increasing the time for direct contact between the patient and healthcare providers (Baffour-Awuah, Mwini-Nyaledzigbor \& Richter 2015). African countries have adopted FANC, while other countries have modified FANC to suit local circumstances (e.g., South Africa, Zimbabwe, Argentina, Saudi Arabia and Cuba) (Ngxongo 2011). The SA Government introduced basic antenatal care (BANC) as a modification of FANC in 2007 to improve on antenatal care services to address the maternal and perinatal mortality rates (Ngxongo 2011).

There is no consensus on the definition of service quality (Dehghan, Shahin \& Zenouzi 2012; Zaim, Bayyurt \& Zaim 2013). Zeithaml, Parasuraman and Berry (1990: 19) define service quality as the extent of discrepancy between customers' expectations or desires and their perceptions. These determinants of service quality are divided into two groups, that is, the tangibles and the intangibles (Zaim, Bayyurt \& Zaim 2013).

\section{Quality of Care Model}

A number of models of quality of care have designed. Some of these are perspective and characteristics models (Raven et al. 2012). According to 
Živaljević, Mitrović, and Petković (2013), any quality improvement or assurance model should either decrease or even eliminate non-conformity.

\section{The Perspective Model}

This model uses the underlying principle that there are different perspectives on the quality of care.

\section{Characteristics Model}

The institute of medicine recently condensed the quality of healthcare characteristics into six main characters: safety, patient centeredness, timeliness, equity, and efficiency (Raven et al. 2012).

\section{Service Quality Gaps}

Information obtained from analysis of service quality gaps plays an important managerial role in finding ways of narrowing service quality gaps and prioritizing which gaps to focus on (Dehghan, Shahin \& Zenouzi 2012). Zeithaml, Parasuraman, and Berry (1990: 19) identified some factors that influence customers' expectations: word of mouth communications, personal needs, past experience and external communications. The SERVQUAL instrument ascertains the level of service quality based on key dimensions. It identifies where gaps in service exist and to what extent. Gap 0ne to four are within the control of an organisation and need to be analysed to determine the causes and changes to be implemented which can reduce or eliminate gap five, that is the discrepancy between customer expectations and their perceptions of the service delivered (Ramseook-Munhurrun, Lukea-Bhiwajee \& Naidoo 2010).

\section{Measuring Service Quality}

Public hospital managers should realise that, to confront the competition of the private sector hospitals, they should measure quality of the service and use the findings as a basis of seeking improvement (Chaniotakis \& Lymperopoulos 2009).

Zarei et al. (2012) state that quality measures can be divided into two: process and outcome. Measuring maternal mortality rate is a good example of an outcome based measure (Janakiraman and Ecker 2010). Zarei et al. (2012) 
equally note that quality in healthcare services entails two dimensions: technical quality (outcome quality) and functional quality (process quality).

Holder and Berndt (2011) highlight the following instruments to have been developed specifically for evaluating medical services:

- Newcastle satisfaction with nursing scale (NSNS).

- Picker patient experience questionnaire (PPEQ).

- The Customer quality index (CQI) cataract questionnaire.

Multi-criteria decision making (MCDM) is another method used to evaluate service quality (Bakİ \& Peker 2015). In light of the above service quality measurement challenges, Lupo (2013) calls for consideration of the analytical hierarchy process (AHP) model. AHP is one of the most considerable MCDM approaches that assist decision makers facing complex problems with multiple conflicting and subjective criteria (Lupo 2013). The other MCDM method is a technique for order preference by similarity to ideal solution (TOPSIS). According to this method, the chosen alternative should be the shortest distance from the positive ideal solution, while being farthest from the negative solution (BakI \& Peker 2015).

\section{Quality Measures in Antenatal Care}

Global efforts to improve maternal and perinatal health outcomes are continuing, however, these efforts largely depend on quality measurements. Measuring the quality of service of obstetric patients has become important, each obstetric admission may affect the health of not one but two individuals and most maternity patients are healthy individuals admitted only for obstetric reasons in whom the goal is nothing but full preservation of health (Crofts et al. 2014).

\section{Maternity Care and Patient Satisfaction}

Patient satisfaction emerged as an area of focus in obstetrics from as early as the 1970s and has since become a commonly reported outcome measure of health-care quality and has obvious implications for organisations and service provision (Clark, Beatty \& Reibel 2015). Clark, Beatty, and Reibel (2015) further emphasise that expectation fulfilment is the most consistent factor associated with childbirth satisfaction. Women's expectations and perceptions 
of maternity care have therefore increasingly become important to healthcare providers, policy makers and administrators as decision making tools (Jenkins et al. 2014).

Hulton, Matthews, and Stones (2000) identified 10 elements that can be used to assess quality in maternal health care services. Six elements related to the provision of care are: Human and physical resources, Referral system, Maternity information systems, use of appropriate technologies, internationally recognized good practice and appropriate management of emergencies. Service quality expectations of antenatal patients are shaped by factors, for example, word-of-mouth communication and what patients hear from others (Nyongesa, Onyango, and Kakai 2014). Atinga and Baku (2013) emphasise on attentiveness and responsiveness as critical factors in the provision of service quality in antenatal care.

\section{Research Methodology}

The quality of antenatal service has been found to play a role in alleviating this problem. A validated SERVQUAL questionnaire was used to gather information on expectations and perceptions of antenatal patients on MPH service quality. In this study simple random sampling was used to select participants in the study, respondents were randomly chosen on each single clinic day amongst the total number of women who attended ANC at MPH maternity department. All under 18 expectant mothers and psychiatric mothers were excluded from the study. A total of 80 questionnaires were handed out over a duration of two weeks where 70 questionnaires were collected properly completed.

\section{Method of Primary Data Collection Used in this Research}

The questionnaire was distributed by the researchers with the help of two nursing sisters. The questionnaire was divided into three sections. The first section was the introduction. The second is the demographic details of the patient. The third section of the questionnaire explored the expectations and perceptions of patients and it contained a total of 15 questions covering the SERVQUAL tool.

\section{Discussion of Results}


A total of 80 questionnaires were distributed, of the 80 questionnaires given out to patients, 70 completed questionnaires were collected back. The response rate was 87.5 percent but not representative enough to be used to conclude for the sample used. Most antenatal patients were aged between 21 and 30 years $(57.15 \%)$. Patients with one child formed most of the proportion at 57 per cent. Seventy-two per cent of antenatal patients had a matric certificate, 14 percent had at least a tertiary qualification. The majority of the pregnant women were not married $(68.57 \%)$ and were booked $(97.14 \%)$. Uses of antenatal care services during pregnancy are high in South Africa with all women utilising antenatal care (Millennium Development Goals Country Report 2013).

\section{Antenatal Service Quality Variables}

Seventy-one per cent of antenatal patients agree that they expect not to be kept waiting unnecessarily. According to Asubonteng, McCleary, and Swan (1996) responsive services reduce waiting times and ensure that patients are promptly attended to. Responsiveness was isolated as an important factor in arresting danger signs and managing obstetric complications.

Antenatal patients agree that they should be assisted according to their needs $(85.71 \%)$. Failure to assist antenatal patients according to their needs, poor relationships with healthcare providers and disrespectful harsh healthcare providers are some of the reasons that discourage women from attending antenatal clinics (Afulani 2015). Factors that underlie provision of quality maternity services are responsiveness and promptness of staff (Atinga \& Baku 2013)). Hill and McCrory (1997) emphasise that women view the presence of modern healthcare technology as a source of security and comforting in the event of complications occurring.

Table 1 indicates that all the respondents agree that MPH maternity department is clean and comfortable. The cleanliness and comfortability of a clinic is regarded as a sign of respect a facility offers to clients and hygienic conditions relieve fears of infection among patients (Hulton, Matthews, and Stones 2000). Appearance of staff and the wards are tangibles in maternity institutions used as cues of expected service (Holder \& Berndt 2011).

Table 1: The maternity department is clean and comfortable 


\begin{tabular}{|l|c|c|c|c|}
\hline & Frequency & Percent & $\begin{array}{c}\text { Valid } \\
\text { percent }\end{array}$ & $\begin{array}{c}\text { Cumulative } \\
\text { percent }\end{array}$ \\
\hline Valid Strongly & 40 & $57.14 \%$ & $57.14 \%$ & 57.14 \\
Agree & 30 & $42.86 \%$ & $42.86 \%$ & 100.00 \\
Agree & 70 & 100.00 & 100.00 & \\
Total & & & & \\
\hline
\end{tabular}

Table 2 shows that 100 percent of the respondents believe that MPH maternity staff show sincerity in solving their problems. However, Mensah, Yamoah, and Adom (2014) noted healthcare providers often have brief encounters with patients and do not show sincere interest and attention to what women talk about.

Table 2: Does the Maternity staff show sincere interest in solving problems?

\begin{tabular}{|l|c|c|c|c|}
\hline & Frequency & Percent & $\begin{array}{c}\text { Valid } \\
\text { Percent }\end{array}$ & $\begin{array}{c}\text { Cumulative } \\
\text { percent }\end{array}$ \\
\hline Valid Strongly & & & & \\
Agree & 20 & 28.57 & 28.57 & 28.57 \\
Agree & 50 & 71.43 & 71.43 & 100.00 \\
Total & 70 & 100.00 & 100.00 & \\
\hline
\end{tabular}

Most of the respondents agree that maternity staff perform their services right the first time. All the respondents agree on maternity staff having adequate knowledge to manage patients. Respect, dignity and equity of care a pregnant woman receives during her stay at a facility is one of the major elements of quality maternity care as alluded to by (Hulton, Matthews \& Stones 2000). 
Munyaradzi Mushunje, Sam Lubbe \& Jan Meyer

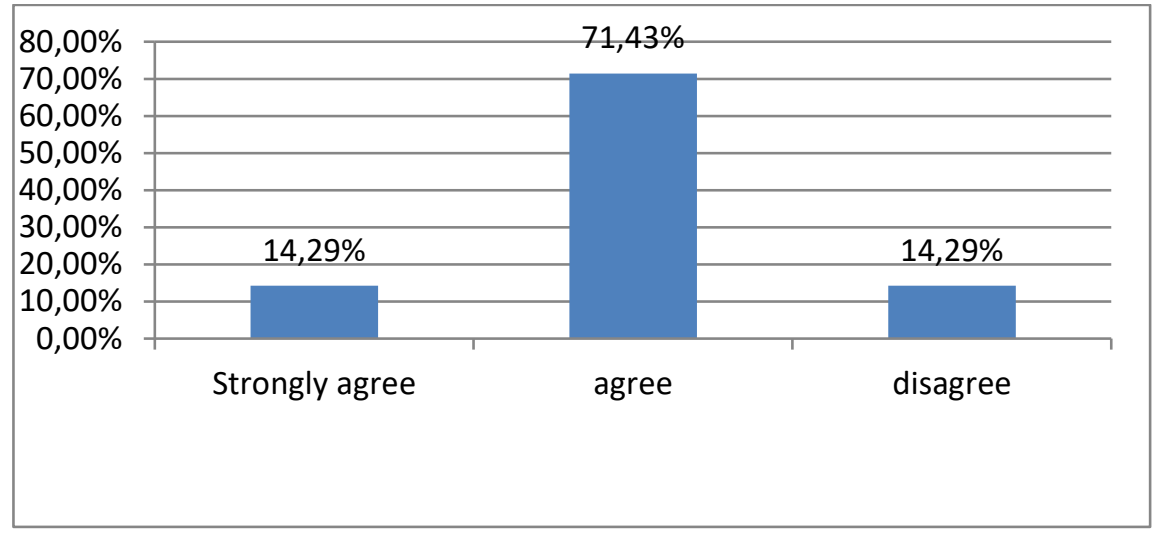

Figure 1: Maternity staff does perform the services right the first time

Table 3 shows a mixed response on the operating hours of the maternity department. The majority $(71.43 \%)$ of respondents concur that maternity doctors and midwives do give each patient individual attention. Antenatal care services should be available every day of the week, this prevents clients either from being turned away or asked to come back another day, a practice which creates opportunity for early ANC attendance (Ngxongo 2011).

Table 3: Maternity department operates within hours convenient to all pregnant patient

\begin{tabular}{|l|c|c|c|c|}
\hline & Frequency & Percent & $\begin{array}{c}\text { Valid } \\
\text { Percent }\end{array}$ & $\begin{array}{c}\text { Cumulative } \\
\text { percent }\end{array}$ \\
\hline Valid Strongly & & & & \\
Agree & 30 & 42.86 & 42.86 & 42.86 \\
Agree & 20 & 28.57 & 28.57 & 71.43 \\
Disagree & 10 & 14.29 & 14.29 & 85.72 \\
Strongly Disagree & 10 & 14.29 & 14.29 & 100.00 \\
Total & 70 & 100.00 & 100.00 & \\
\hline
\end{tabular}




\section{Relationship between Variables}

Most of the patients were para one, meaning they already had one baby before. There was a negative correlation -0.379 between parity and Maternity staff do have adequate knowledge to manage patients. It means as parity increased the more patients felt maternity staff did not have adequate knowledge to manage patients. The majority agreed that MPH maternity wing has modern looking equipment. There is a correlation of 0.567 with maternity staff should offer prompt attention to patients. The more antenatal patients notice modern equipment in the clinic, the more they expect prompt action from doctors and midwives.

Many antenatal patients $(71.40 \%)$ expected prompt attention from maternity staff. There was a positive correlation +0.567 with patients should not be kept waiting unnecessarily. All antenatal patients expected prompt attention and there was a positive correlation +0.567 with the variable: maternity staff do have adequate knowledge to manage patients. The more antenatal patients expected prompt attention, the more they felt maternity staff do have adequate knowledge to manage patients.

\section{Research Questions, Conclusion and Recommendations}

This section presents a discussion on expectations and perceptions raised by antenatal patients.

\section{Research Questions}

\section{What expectations do antenatal patients have on Mafikeng}

Provincial Hospital service quality?

Nyongesa, Onyango, and Kakai (2014) noted that service quality expectations of antenatal patients are shaped by a number of factors, for example, word of mouth communication and what patients hear from others.

\section{Do you expect MPH maternity staff to demonstrate willingness to help patients and provide prompt services?}

All antenatal patients indicated they don't expect to be kept waiting. All antenatal patients indicated they expected prompt attention from maternity 
staff and agreed that maternity staff should offer prompt attention to patients. This finding is further underpinned by Amin \& Nasharuddin (2013) when they emphasize responsiveness as a critical factor that underlies service provision in maternity services by reducing waiting times and offering prompt services.

This finding may possibly mean that patients have adjusted expectations of the public healthcare system since the volumes of patients overwhelm service providers. The desire not to be kept waiting unnecessarily increased with age, this finding where older patients felt they should not be kept waiting unnecessarily indicates that as patients become older the more they feel they are at risk of complications. This finding emphasises the importance of responsiveness in antenatal care service.

\section{Do you expect MPH maternity staff to be courteous and to communicate trust and confidence in patients?}

All antenatal patients expressed the need to feel secure while in the maternity department. All antenatal patients indicated they expect maternity staff to be polite and courteous to patients. Responses to questions indicate the importance of assurance in the provision of maternity services. Courteous and respectful and caring staff create comfortable environments that promote pregnant mothers to discuss their problems with service providers (Nyongesa, Onyango \& Kakai 2014).

\section{What is the quality of the physical facilities at MPH maternity wing, including appearance of its personnel?}

The majority of antenatal patients strongly agreed that MPH maternity department has modern looking equipment. The MPH maternity department was coined as clean and comfortable by all antenatal patients. All the maternity patients indicated that MPH staff are professional and neatly dressed. Above findings indicate that the appearance of Maternity personnel and its physical facilities overwhelmingly satisfy its antenatal patients. These findings are in line with the findings of Ejigu, Woldie, and Kifle (2013) when they found out that comfortable waiting rooms and clean toilets were amongst reasons associated with patient satisfaction. Holder and Berndt (2011) emphasize that tangibles are the only tangible cues in service quality provisioning and thus 
they are important cues used to evaluate expected service before and satisfaction after receiving the service.

\section{Does MPH maternity staff deliver their services dependably and accurately?}

All maternity patients felt that maternity staff is dependable and accurate in their dealings with the patients and that maternity staff show sincerity in solving their problems. The majority of respondents $(85.72 \%)$ believe that maternity staff do perform services right the first time, while 14.29 per cent disagreed to this notion. While all patients agree that maternity staff do show sincerity in attending to their problems, there was a mixed response to the ability of maternity staff performing services right the first.

As noted above 14.29 percent of patients disagree that maternity staff perform services right. Nesbitt et al. (2013) noted that evaluation of maternity care is a complicated and culturally sensitive issue where most users are healthy, but serious complications can develop unpredictably. It therefore is very important that the right services are performed right from the onset, failure of which may result in complications to both mother and baby.

\section{Does MPH maternity staff provide individualised attention to patients?}

Maternity patients generally feel maternity staff do provide individualised attention to patients. All the antenatal patients feel that maternity staff do care for them, 71.43 per cent simply agreed, while 28.57 per cent strongly agreed that maternity staff had a caring attitude towards patients. Janakiraman \& Ecker (2010) isolated caring/empathy of healthcare professionals as elements of quality in maternity care. Antenatal patients are satisfied by the individualised treatment they receive from the High-Risk Clinic. This finding is in contradiction with Manithip et al. (2013) who reported that healthcare givers spend limited time with antenatal mothers, paying less attention and not offering opportunities for women to ask questions. Convenience of operating hours of High Risk Clinic received a mixed response. Shortage of staff and unavailability of supporting services like ultrasonography may be contributory factors. The current national call on operating times of Antenatal clinics as 
noted by Ngxongo (2011) is to ensure that antenatal care services are offered every day of the week.

\section{Does maternity staff have adequate knowledge to manage patients?}

All antenatal patients feel that the doctors and nursing staff have adequate knowledge to manage their conditions. This finding clearly indicates that antenatal patients feel assured and safe in the hands of maternity staff of Mafikeng Provincial Hospital. Janakiraman and Ecker (2010) also isolated empathy as an important quality measure in maternity services. In this study, the more maternity staff promptly attended to patients according to their needs, the more patients felt that maternity staff had adequate knowledge to manage them.

\section{Recommendations}

Taking into consideration the findings of this research and literature reviewed, five recommendations are proposed. These recommendations have been identified by the researcher as gaps in maternity service quality.

\section{Training of Healthcare Personnel on Service Quality}

Service Quality is a field that has generally received little attention despite its significant role in organisational success and profitability. The researcher therefore recommends that healthcare personnel must undergo in-service training in service quality. This training will assist in ensuring that service providers are able to meet the expectations of their patients. This is supported by Amin and Nasharuddin (2013). The training of healthcare professional can be championed by the Hospital as well as the Provincial Health Office. Improvements in quality of services provided to maternity women can only be realised by continuous training.

\section{Implementing Communication Channels and Systems between Maternity Service Providers and the Patients}

Communication is an important tool in shaping of service quality expectations. 
The researcher therefore recommends that MPH management puts in place a system that ensures patients are informed of procedures, hospital protocols and any special events or developments that may impact on the quality of service to be delivered. The maternity department must have visible signage and appoint a dedicated person who assists with ushering patients and ensuring that patients are assisted accordingly. Overall, this was also supported by BaffourAwuah et al. (2015).

\section{Appointing Doctors and Nursing Staff that have a Passion for Maternity}

Staff appointed to work in maternity must have a strong passion and liking for maternity. It is no secret that different people have different interests. Passionate healthcare personnel show empathy and a caring attitude to their patients and will always endeavour to perform services right the first time. Maternity care is therefore not only defined by qualifications, but service providers must have a passion for pregnant mothers.

\section{Managerial Resource Allocation to Investing in Tangibles}

Mafikeng Provincial Hospital maternity wing should invest heavily in the tangibles of the Clinic, especially maternity equipment. Other aspects of tangibles like cleanliness and comfort of the clinic, neatness and professional appearance of staff need to be emphasised.

In this research, through correlation studies, tangibles emerged as a major driver of other quality attributes. This finding is supported in literature Crofts et al. (2014) noted pregnant women associate the presence of modern equipment in clinics with security in the event of complications.

\section{Relook into Operating Hours of the High-Risk Clinic}

The results quite evidently show a mixed response regarding the convenience of operating times of the High-Risk Clinic. The researcher therefore recommends that the operating hours of the clinic be revisited in a way that will suit all pregnant women. Other women are working and cannot afford to take the whole day off from work. The current call is to offer antenatal care 
services daily, this one stop shop or supermarket approach has been found to offer convenience to the pregnant mother notwithstanding current shortages of staff and mass resignations of staff from the public sector.

\section{Conclusion}

This research sought to assess the quality of antenatal care services at Mafikeng Provincial Hospital through determining service quality expectations and perceptions of antenatal patients. The research found that antenatal patients have high responsive expectations from maternity staff. Antenatal patients also expressed a high desire to be treated politely and courteously by maternity staff and the needy to feel secure while using the facilities of the maternity department.

The findings of this study have provided information on important service quality attributes that pregnant women value most. It also managed to assess antenatal patient perceptions of MPH service quality. The findings of this study have added to the body of knowledge on antenatal service quality and have also provided a platform for a number of recommendations on how managers can improve upon antenatal service quality to curtail maternal mortality rate.

\section{Acknowledgements}

We would like to thank the Chief Executive Officer and Management of Mafikeng Provincial Hospital for permitting this research to be carried out in the hospital. Many thanks to Antenatal Clinic Sisters for their assistance with data collection.

\section{References}

Afulani, P.A. 2015. Rural/Urban and Socioeconomic Differentials in Quality of Antenatal Care in Ghana. PLoS ONE 10 2:1-28.

https://doi.org/10.1371/journal.pone.0117996

Amin, M. \& S.Z. Nasharuddin 2013. Hospital Service Quality and its Effects on Patient Satisfaction and Behavioural Intention. Clinical Governance: An International Journal 18,3:238 - 254. doi: 10.1108/CGIJ-05-20120016. https://doi.org/10.1108/CGIJ-05-2012-0016 
Amnesty International Report 2013. Amnesty International Report. Canada: Amnesty International.

Asubonteng, P., K.J. McCleary \& J.E. Swan 1996. SERVQUAL Revisited: A Critical Review of Service Quality. Journal of Services Marketing 10, 6:62 - 81. https://doi.org/10.1108/08876049610148602

Atinga, R.A. \& A.A. Baku. 2013. Determinants of Antenatal Care Quality in Ghana. International Journal of Social Economics 40,10:852 - 865. https://doi.org/10.1108/IJSE-2011-0075

Baffour-Awuah, A., P.P. Mwini-Nyaledzigbor \& S. Richter 2015. Enhancing Focused Antenatal Care in Ghana: An Exploration into Perceptions of Practicing Midwives. International Journal of Africa Nursing Sciences 2: 59 - 64. https://doi.org/10.1016/j.ijans.2015.02.001

Bakİ, Birdogan bbaki ktu edu tr, and İSkender iskenderpeker gumushane edu tr Peker. 2015. An Integrated Evaluation Model for Service Quality of Hospitals: A Case Study from Turkey. Journal of Multiple-Valued Logic \& Soft Computing 24,5/6: 453 - 474.

Burton, R. \& L. Acquah 2014. Women's Health and Human Rights 104. Women\&\#039;s health; Human Rights.

https://doi.org/10.7196/SAMJ.8725

Chaniotakis, I.E. \& C. Lymperopoulos 2009. Service Quality Effect on Satisfaction and Word of Mouth in the Health Care Industry. Managing Service Quality: An International Journal 19,2: 229 - 242.

https://doi.org/10.1108/09604520910943206

Clark, K., S. Beatty \& T. Reibel 2015. 'What women want': Using Image Theory to Develop Expectations of Maternity Care Framework. Midwifery 31,5: 505 - 511.

https://doi.org/10.1016/j.midw.2014.12.011

Crofts, J., J. Moyo, W. Ndebele, S. Mhlanga, T. Draycott \& T. Sibanda. 2014. Adaptation and Implementation of Local Maternity Dashboards in a Zimbabwean Hospital to Drive Clinical Improvement. Bulletin of the World Health Organization 92,2: 146 - 152.

https://doi.org/10.2471/BLT.13.124347

Dehghan, A., A. Shahin \& B. Zenouzi 2012. Service Quality Gaps \& Six Sigma. Journal of Management Research 4,1: 1 - 11.

https://doi.org/10.5296/jmr.v4i1.887

Ejigu, T., M. Woldie \& Y. Kifle 2013. Quality of Antenatal Care Services at Public Health Facilities of Bahir-Dar Special Zone, Northwest Ethiopia. 
BMC Health Services Research 13,1: 1 - 15. doi: 10.1186/1472-6963-13443. https://doi.org/10.1186/1472-6963-13-443

Fagbamigbe, A.F. \& E.S. Idemudia 2015. Assessment of Quality of Antenatal Care Services in Nigeria: Evidence from a Population-based Survey. Reproductive Health 12,1: 88 - 88.

https://doi.org/10.1186/s12978-015-0081-0

Hill, F.M. \& M.L. McCrory 1997. An Attempt to Measure Service Quality at a Belfast Maternity Hospital: Some Methodological Issues and Some Results. Total Quality Management 8,5: 229 - 242.

https://doi.org/10.1080/0954412979488

Holder, M. \& A. Berndt 2011. The Effect of Changes in Servicescape and Service Quality Perceptions in a Maternity Unit. International Journal of Healthcare Quality Assurance 24,5: 389 - 405. https://doi.org/10.1108/09526861111139205

Hulton, L., Z. Matthews \& R.W. Stones 2000. A Framework for the Evaluation of Quality of Care in Maternity Services.

Janakiraman, V. \& J. Ecker 2010. Quality in Obstetric Care: Measuring what Matters. Obstetrics \& Gynecology 116,3: 728 - 732.

https://doi.org/10.1097/AOG.0b013e3181ea4d4f

Jenkins, M.G. J.B. Ford, J.M. Morris \& C.L. Roberts 2014. Women's Expectations and Experiences of Maternity Care in NSW - What Women Highlight as most Important. Women and Birth 27,3: 214 - 219. https://doi.org/10.1016/j.wombi.2014.03.002

Lori, J.R., C.Hwa, Y. Dahlem, J.V. Ackah \& R.M.K. Adanu. 2014. Examining Antenatal Health Literacy in Ghana. Journal of Nursing Scholarship 46,6: 432 - 440. doi: 10.1111/jnu.12094.

https://doi.org/10.1111/jnu.12094

Lupo, T. 2013. A Fuzzy ServQual Based Method for Reliable Measurements of Education Quality in the Italian Higher Education Area. Expert Systems with Applications 40,17: 7096 - 7110.

https://doi.org/10.1016/j.eswa.2013.06.045

Manithip, C., K. Edin, A. Sihavong, R. Wahlström \& H. Wessel 2013. Poor Quality of Antenatal Care Services - Is Lack of Competence and Support the Reason? An Observational and Interview Study in Rural Areas of Lao PDR. Midwifery 29,3: 195 - 202.

https://doi.org/10.1016/j.midw.2011.12.010

Mensah, P., E.E. Yamoah \& K. Adom 2014. Empirical Investigation of Service 
Quality in Ghanaian Hospitals. European Journal of Business and Management 6,18: 157 - 178.

Millenium Development Goals Report 2013. The Millenium Development Goals Report. United Nations.

Naariyong, S., K. Poudel, M. Rahman, J. Yasuoka, K. Otsuka \& M. Jimba 2012. Quality of Antenatal Care Services in the Birim North District of Ghana: Contribution of the Community-Based Health Planning and Services Program. Maternal \& Child Health Journal 16,8: 1709 - 1717. https://doi.org/10.1007/s10995-011-0880-z

Nesbitt, R.C., T.J. Lohela, A. Manu, L. Vesel, E. Okyere, K. Edmond, S. Owusu-Agyei, B.R. Kirkwood \& S. Gabrysch 2013. Quality along the Continuum: A Health Facility Assessment of Intrapartum and Postnatal Care in Ghana. PLoS ONE 8,11: e81089.

https://doi.org/10.1371/journal.pone.0081089

Ngxongo, T.S. Patience 2011. Factors Influencing Successful Implementation of Basic Ante Natal Care Programme in Primary Health Care Clinics in eThekwini District, KwaZulu-Natal. Durban University of Technology.

Nyongesa, M., M. Wandera, R. Onyango \& R. Kakai 2014. Determinants of Clients' Satisfaction with Healthcare Services at Pumwani Maternity Hospital in Nairobi-Kenya. International Journal of Social and Behavioral Sciences 2,1: 011 - 117.

Ramseook-Munhurrun, P., S.D. Lukea-Bhiwajee \& P. Naidoo 2010. Service Quality in the Public Service. International Journal of Management and Marketing Research 3,1: 37 - 50.

Raven, J.H., R.J. Tolhurst, S. Tang \& N. van den Broek 2012. What is Quality in Maternal and Neonatal Health Care? Midwifery 28,5:e676-e683. https://doi.org/10.1016/j.midw.2011.09.003

Villadsen, S.F., D. Negussie, A. GebreMariam, A. Tilahun, H. Friis \& V. Rasch 2015. Antenatal Care Strengthening for Improved Quality of Care in Jimma, Ethiopia: An Effectiveness Study. BMC Public Health 15,1:1 13. https://doi.org/10.1186/s12889-015-1708-3

Zaim, H., N. Bayyurt \& S.S. Zaim 2013. Service Quality and Determinants of Customer Satisfaction in Hospitals: Turkish Experience. International Business \& Economics Research Journal (IBER) 9,5. https://doi.org/10.19030/iber.v9i5.8145

Zarei, A., M. Arab, A.R. Forushani, A. Rashidian \& S.M.G. Tabatabaei 2012. Service Quality of Private Hospitals: The Iranian Patients' Perspective. 
Munyaradzi Mushunje, Sam Lubbe \& Jan Meyer

BMC Health Services Research 12,31: 2 February 2012 - 2 February 2012. https://doi.org/10.1186/1472-6963-12-31

Zeithaml, V.A., A. Parasuraman \& L.L. Berry 1990. Delivering Quality Service: Balancing Customer Perceptions and Expectations. Simon and Schuster.

Živaljević, A., Ž. Mitrović \& M. Petković 2013. Conceptual and Mathematical Model for Quality Improvement in Health Care. The Service Industries Journal 33,5: 516 - 541. https://doi.org/10.1080/02642069.2011.622368

Munyaradzy Mushunje Graduate School of Business \& Government Leadership North West University Mafikeng South Africa drmunyaradzim@gmail.com

Sam Lubbe Faculty of Management Sciences Mangosuthu University of Technology Umlazi

South Africa

Lubbe.samuel@mut.ac.za

Jan Meyer NWU Business School North West University Mafikeng South Africa Jan.meyer@nwu.ac.za 